Publicación semestral. ISSN 2215-4906

Volumen 81 - Número 1

Revista de las artes Julio - Diciembre 2021

\title{
Miradas contemporáneas y abordajes museográficos desde lo local en la exposición Obreras. Trabajo en el frigorífico y barrio Saladillo
}

Contemporary Looks and Museographic Approaches from the Local in the Exhibition Obreras. Trabajo en el frigorífico y barrio Saladillo

María Cecilia Olivari Alejandra Panozzo Zenere 


\title{
Miradas contemporáneas y abordajes museográficos desde lo local en la exposición Obreras. Trabajo en el frigorífico y barrio Saladillo
}

\author{
Contemporary Looks and Museographic Approaches \\ from the Local in the Exhibition Obreras. Trabajo en \\ el frigorífico y barrio Saladillo
}

\author{
María Cecilia Olivari ${ }^{1}$ \\ Instituto de Estudios Críticos en Humanidades, Universidad del Rosario (IECH, CONICET-UNR) \\ Rosario, Argentina \\ Alejandra Panozzo Zenere ${ }^{2}$ \\ Centro de Estudios Visuales Latinoamericanos, Universidad del Rosario (CEVILAT-IECH, UNR) \\ Rosario, Argentina
}

Recibido: 12 de marzo de $2020 \quad$ Aprobado: 10 de febrero de 2021

\section{Resumen:}

El artículo se propone explorar las estrategias museográficas y visuales que se ponen en juego en la exposición Obreras. Trabajo en el frigorífico y barrio Saladillo (Argentina: Museo de la Ciudad de Rosario Wladimir Mikielevich, 2019). La exploración de este caso abre una línea alternativa de práctica curatorial y museográfica con perspectiva género aplicada a la historia que, a su vez, focaliza en experiencias significativas a nivel local. Desde una perspectiva transdisciplinar, se abordará este caso desde una ampliación de la museología de la idea (García Blanco, 1999) hacía los giros temáticos (Guasch, 2016) y las constelaciones de imágenes (Piñero, 2013; Giunta, 2016), buscando indagar en la utilización de recursos y tipologías museográficas. Esta aproximación a los modos de exhibir en la actualidad (Panozzo \& Olivari, 2020) permite contemplar formas diversas de interpelar al público visitante en función de generar una experiencia museal ampliada.

1 Becaria doctoral del Instituto de Estudios Críticos en Humanidades (IECH, CONICET-UNR). Licenciada en Bellas Artes por la Universidad Nacional de Rosario (UNR). ORCID: 0000-0002-20891934. Correo electrónico: mceciliaolivari@gmail.com

2 Docente e investigadora en Centro de Estudios Visuales Latinoamericanos, CEVILAT-IECH-UNR. Doctora en Comunicación Social por la Universidad Nacional de Rosario. ORCID: 0000-00031929-0434. Correo electrónico: panozzo.a@gmail.com 
Palabras clave: archivo; exposición; Estudios Visuales; historiografía local; museo

\section{Abstract:}

The article attempts to explore the museographic and visual strategies involved in the exhibition "Obreras: Trabajos en el frigorífico y barrio Saladillo." (Argentina: Museo de la Ciudad de Rosario Wladimir Mikielevich, 2019). The exploration of this case opens an alternative line of curatorial and museographic practices with a gender perspective applied to history, that also focuses on meaningful experiences at the local level. From a transdisciplinary perspective, this case will be addressed based on a museology of the idea (García Blanco, 1999) expanded to the thematic turns (Guasch, 2016) and the constellations of images (Piñero, 2013; Giunta, 2016), seeking to investigate the use of museographic resources and typologies. This approach to the ways of exhibiting today (Panozzo \& Olivari, 2020), allows to contemplate different means to challenge the visiting public in order to generate an amplified museal experience.

Keywords: archive; exposition; Visual Studies; local historiography; museum 
Miradas contemporáneas y abordajes museográficos desde lo local en

Artículo la exposición Obreras. Trabajo en el frigorífico y barrio Saladillo

\section{Modos de exhibir: registros de visualidad y experimentación en el museo}

El análisis de la exposición dentro del museo marca un panorama jerarquizado y categorizado en la gestión y presentación de lo visible. En este sentido, nos interesa indagar en el modo en que se ponen en juego la visualidad de las piezas y el conjunto de elementos que se despliegan en el espacio expositivo. Este tipo de aproximación permite indagar en el por qué algo es exhibible, pero también profundizar en el cómo los elementos se dan a ver en las exposiciones. Para abordar este objeto de análisis, los Estudios Visuales (Guasch, 2003; Bal, 2004; Mitchell, 2009; Brea, 2015) proponen un enfoque que supera las categorías cerradas recurriendo, como propone María Elena Lucero, a diversos sistemas de observación y perspectivas de acercamiento en el análisis cultural (Lucero, 2016).

Trabajar desde este tipo de enfoque posibilita la ruptura con las narrativas totalizantes inherentes al estudio histórico de las artes que se ha institucionalizado en los museos durante los siglos XIX y XX. De esta manera, se habilita un espacio de discusión para nuevos abordajes, promoviendo, además, enlaces entre distintas áreas del conocimiento -estudios sobre historia cultural y social, abordajes que contemplen cuestiones de género, raza y clase, estudios sobre curaduría, medios e imágenes- que estructuran otro tipo de andamiaje teórico-metodológicos.

Nos focalizamos en la idea de que las exposiciones plantean distintos modos de presentación que, a su vez, proponen múltiples interacciones con los elementos visuales y museográficos, lo que confluye en diversas formas de experimentación dentro del museo y de la muestra. En los inicios, específicamente en los museos de arte, las exposiciones presentaban "un montaje expositivo ... muy abigarrado, tapizando en ocasiones las paredes de suelo a techo. Esta fórmula proporcionaba 'una impresión de esplendida abundancia' ... pero dificultaba la apreciación de las piezas individualmente” (Jiménez Blanco, 2014, p. 64).

En el siglo XX, en cambio, se creó una propuesta exhibitiva basada en el estilo de Alfred $\mathrm{H}$. Barr Jr. que inauguró la marca del Museum of Modern Art (MoMA). A partir de esto, las exposiciones de arte fueron asociándose con el modelo del "Cubo Blanco" como espacio ascético e incontaminado (O’Doherty, 1999); allí las piezas se disponían "simétricamente en una línea neta horizontal a la altura de los ojos, sobre paredes tapizadas en un beige claro monacal” (Balser, 2018, p. 50). En este tipo de presentación expositiva, el rol de los visitantes se reducía a la contemplación y su experiencia se anclaba en la tradicional idea de espectador, es decir, haciendo referencia a una persona que se vincula desde la iteración o el hábito de observar (Bayón \& Cuenca Amigo, 2019). 
A fines de la década de 1970, la implicación de los públicos se amplía y su participación comienza a ser esencial; al mismo tiempo, se producen relecturas del relato expositivo a partir de un esquema museológico basado en la idea (García Blanco, 1999). Esto, sumado a la diversificación de los formatos en las piezas de arte a partir de fines de los años 1960 -con prácticas ligadas a los procesos y las instalaciones, el cuerpo y lo performático, la producción conceptual y objetual, y las articulaciones con la tecnología y el activismo, entre otros (Guasch, 2000)-, hace que las condiciones de los montajes tradicionales resulten insuficientes y, necesariamente, deba apelarse a otros recursos o medios en el espacio expositivo.

Por último, en este breve recorrido histórico, no podemos dejar de señalar que, sobre finales del siglo XX, los visitantes no solo buscaban realizar un aprendizaje o vincularse estéticamente con las obras en sus recorridos por las exposiciones, sino además aventurarse a percepciones más atractivas. Consecuentemente, una de las características que comienza a manifestarse es el acoplamiento de los museos a las lógicas mercantiles de esparcimiento y ocio que imponen el imperativo de la atracción para sostenerse, ser elegidos y no perecer dentro del circuito cultural.

A continuación, profundizaremos en las exposiciones a partir de una línea que actualiza la museología de la idea. Para ello, recurrimos a dos propuestas de trabajo que nos permiten abordar las dinámicas visuales y museográficas actuales: los giros temáticos en el contexto global (Guasch, 2016) y las constelaciones de imágenes (Piñero, 2013; Giunta, 2016). En primer lugar, la idea de giros temáticos es trabajada por Anna María Guasch (2016) para reflexionar sobre las exposiciones en la era de lo global. Su propuesta sugiere abordar la producción artística imbricada a dimensiones sociales, culturales, económicas, etnográficas y ecológicas que se hacen presentes como temas, pero también como estrategias metodológicas. Entendemos esta clasificación de Guasch (2016) como superficies de reflexión permeables entre sí que desdibujan las taxonomías temáticas rígidas y no como como una demarcación de límites absolutos. En cuanto a la segunda propuesta, el formato constelar surge, fundamentalmente, de las relecturas contemporáneas (Piñero, 2013; Giunta, 2016) de los ejercicios benjaminianos en el Libro de los pasajes (Benjamin, 2005). En el caso de las exposiciones, lo constelar se corresponde con un sistema de núcleos conectados que articulan y reúnen elementos diversos a partir de agrupamientos por tópicos, temas u otros. En este tipo de propuestas, la singularidad del objeto queda desplazada cobrando valor en el conjunto que lo aloja, esto es, dentro de una red abierta de relaciones que retroalimentan sus lecturas potenciales. 
Miradas contemporáneas y abordajes museográficos desde lo local en

Artículo la exposición Obreras. Trabajo en el frigorífico y barrio Saladillo

En el encuentro de estas dos propuestas, las exposiciones en el marco de la contemporaneidad ya no constituyen modelos fijos, sino que sus dinámicas se reconfiguran a partir de las necesidades específicas de los objetos, los espacios y los actores que en ellos intervienen. Por tanto, lo que hemos llamado modos de exhibir (Panozzo \& Olivari, 2020) adquiere un carácter situado que parte de lo particular y se abre a reflexiones generales. Asimismo, en esta línea, se deja de lado la experiencia general en la exposición relacionada solamente con la cuestión de lo perceptivo del objeto museológico real en el espacio. Este abordaje -que se articulaba con funciones propias de las tareas del museo- puede asociarse en la exposición con la experiencia estética (Dewey, 2008) en un sentido tradicional. En este tipo de encuentro con las piezas, se produce un impacto por la autoridad cultural o histórica, o por tratarse de objetos que desencadenan recuerdos, gustos o goce. A su vez, esta práctica se vincula con la dimensión educativa que constituye un rasgo específico de la propia institución cultural y de este formato de exposición (Falk \& Dierking, 2013). Ambas condiciones, la experiencia estética y la educativa, presuponen un saber erudito sobre la Historia del Arte, se encuentre presente o esté falta.

Por el contrario, la apertura que proponemos con la actualización de la museología de la idea no solo admite un conocimiento formal y disciplinar sobre las imágenes, sino un conocimiento vinculado a la experiencia cotidiana con los medios, la cultura visual y las visualidades en circulación (Mitchell, 2009). Dichas experiencias confluyen, por consiguiente, en un tipo de tránsito en la exposición que incorpora dinámicas de la producción de imágenes y su mediatización, por ejemplo, la captura en formato selfie, la utilización de hashtags al momento de compartir en redes sociales y el streaming en vivo del recorrido en el museo. Estas prácticas inscritas dentro de las lógicas de las redes sociales también son promovidas por los museos, ampliando el mise-en-scéne ${ }^{3}$ espectacular y la exuberancia por fuera de los muros de los establecimientos patrimoniales (Huyssen, 2001).

En esta línea podemos mencionar algunos aspectos del diseño en la exposición que se apropian de otros para direccionar la experiencia que allí acontece más allá de la inclusión de medios secundarios -texto en sala, vitrinas, etiquetas-, recursos informativos o audiovisuales -diarios, revistas, periódicos, archivos, documentos, registros- que buscaban

${ }^{3}$ Esta expresión según Andreas Huyssen (2001) refiere a la espectacularidad de la puesta en escena como una política de exhibición y contemplación orientada a la masificación y espectacularización del museo para la ampliación de los públicos.

ESCENA. Revista de las artes, 2021, Vol. 81, Núm. 1 (julio-diciembre), pp. 63-84 
hacer más accesible la narrativa. En los últimos años, también se apeló a nuevos dispositivos museográficos no solo para desarrollar la idea, sino en función de generar estímulos y emociones que confluyan en la creación de espacios temáticos. Las muestras se apropiaron, por ejemplo, de herramientas del diseño teatral incorporando escenografías. Allí, lo formal, lo temático y los medios son componentes inseparables de un "todo experiencial" (Bofinger, 2010 citado en EVE, 2019). Esto reconstruye las sensaciones, tanto físicas como temporales, y el cuerpo de los públicos abandona la mera contemplación para operar desde los sentidos. El tránsito del cuerpo del visitante en el espacio se convierte en la fuente de un conjunto de fuerzas que definen nuevos estímulos y, con ello, nuevas trayectorias. Asimismo, algunos de los elementos o piezas que conforman las escenografías pasan a ser atractores que suscitan la atención en recorridos guiando comportamientos posibles en la exposición.

Algunas de las modificaciones señaladas demarcan una experiencia diferenciada en las exposiciones de los museos de arte a partir de cambios en los lenguajes y técnicas de las producciones artísticas, el posible uso de las tecnologías o los nuevos recorridos o narrativas a partir del uso de otro tipo de dispositivos museográficos. Sin embargo, en otras tipologías también acontecen modificaciones en la experiencia de las exposiciones que ayudan a profundizar el rompimiento con la idea de objeto y de narrativa historicista.

En este sentido, Jorge Wagensberg (2001) -en referencia a los museos de cienciasostiene que, en la experiencia de la exposición, el visitante ya no solo convive con piezas reales sino también con fenómenos, vinculando a los primeros con los elementos materiales que ocupan el espacio y a los segundos con la experimentación en la visita. A partir de ello, este autor propone una nueva museografía basada en un método de interactividad emocional. Esta se encuentra compuesta de la interactividad manual -vinculada al experimento-, la interactividad mental -aquella que supone una transformación de los visitantes, un antes y un después de la visita- y la interactividad emocional -asociado a las posibles resonancias sensibles del suceso expositivo en el visitante, a partir de matices estéticos, éticos, morales, históricos o simplemente de la vida. De esta manera, la exposición diversifica los registros de experimentación, habilitando ofertas de tránsito controladas, pero también otras abiertas que, en cambio, surgen a partir de la interacción de los visitantes con el espacio y el montaje. A partir de estas últimas es que podemos hablar de la diversificación de los regímenes espectatoriales, es decir, los diversos modos de encarnar el rol de visitante según la experiencia de cada individuo que recorre una exposición (Verón, 2013). 
Miradas contemporáneas y abordajes museográficos desde lo local en

Artículo la exposición Obreras. Trabajo en el frigorífico y barrio Saladillo

En definitiva, los habilitantes propios de las distintas tipologías de museo buscan, en algún sentido, abrir las posibilidades para repensar la presentación museográfica, ya no solo desde los objetos sino también desde los distintos elementos que se dan a ver. A continuación, desarrollaremos un caso que, desde lo local, propone algunos de estos lineamientos en su práctica curatorial y museográfica, al mismo tiempo que pondera circuitos descentralizados y federales, para pensar la experiencia en el espacio expositivo en la actualidad.

\section{Obreras. Trabajo en el frigorifico y barrio Saladillo en el Museo Wladimir Mikielievich}

El Museo de la Ciudad de Rosario (Argentina) fue creado en 1981 y se encuentra ubicado en la ex-administración de Parques y Paseos y la Escuela de Aprendices de Jardineros en el centro del Parque de la Independencia (Calvi \& D'Amelio, 2006). En el año 2004, fue nombrado "Wladimir Mikielievich" por el Consejo de la ciudad en homenaje a su rol destacado en el proyecto de formación de un "Museo de Historia de Rosario", que se concretó luego en este museo. Al igual que numerosas entidades que se crearon a partir de la puesta en valor del patrimonio local, este Museo fue asociado, en sus comienzos, con los museos de historia que reflejan la memoria regional, la de su comunidad de origen o aquellos que representan la vida cotidiana de los primeros habitantes. Según esta lógica museográfica, las exposiciones se ofrecían como una acumulación de objetos -tuvieran estos atributos similares o heterogéneos- con salas abarrotadas y la colección completa a la vista. Sin embargo, esta condición determina un concepto más nostálgico que histórico.

Sobre principios del siglo XXI, se continua esta línea temática pero se focaliza en figuras locales, al promover otro tipo de muestras como: Memorias del río (2007), que delinea cruces con lenguajes estéticos que incorporan la literatura como elemento expositivo; Emilia Bertolé (2005), cuyo guion museográfico está estructurado emulando una secuencia fílmica, y Ciudad sin bordes (2004), que apela a la incorporación de investigaciones de profesionales especializados sobre objetos de la colección. A quince años de estos antecedentes, se inicia una nueva etapa, que busca reflotar algunas dinámicas de ese momento para reposicionar al Museo dentro del circuito de instituciones rosarinas, pero con un sello personal que busca acoplarse a las nuevas dinámicas de los museos con sus comunidades. La nueva gestión, en palabras de su actual director ${ }^{4}$, se propone continuar

${ }^{4}$ A fines de 2018, el Lic. Nicolás Charles asume la dirección del Museo mediante un concurso público municipal y ocupó dicho cargo por un periodo de cinco años.

ESCENA. Revista de las artes, 2021, Vol. 81, Núm. 1 (julio-diciembre), pp. 63-84 
la línea que hace años que la Secretaría de Cultura y Educación viene manteniendo y que es incorporar la perspectiva de género en las instituciones culturales. Una impronta que está avanzando cada vez más fuerte y que nos proponemos abordar. Pensamos en un museo que interpele, que problematice y que tome temáticas transversales a toda la ciudad (citado en Inaugura una muestra sobre obreras de frigoríficos en el Museo de la Ciudad, 11 de abril de 2019, párr. 6).

Bajo esta premisa, se celebró la muestra Obreras. Trabajo en el frigorífico y barrio Saladillo (2019), curada por Laura Pasquali ${ }^{5}$, junto al equipo conformado por Beatriz Argiroffo, Gisela Figueroa y Luisina Agostini y al personal de la institución, la cual estuvo abierta al público desde el 17 de abril al 19 de agosto de 2019. Desde ese mismo día, en el invernadero del museo, también se presentó la selección de fragmentos audiovisuales Fugas y resistencias. Trabajadoras: imagen y representación o hacer visible lo invisible, a cargo de Mónica Fessel y Carolina Rimini (2019).

Para la muestra Obreras se dispusieron diversos materiales del Archivo fotográfico del Museo de la Ciudad, material bibliográfico y fotográfico del Museo 1871 Berisso (Argentina) -que contenía objetos vinculados al Frigorífico Swift- y la colección del Museo Dr. Raúl Malatesta de Villa Gobernador Gálvez. Además, se incorporó la obra del artista rosarino Aldo Magnani junto a fotografías de los acervos privados de los historiadores barriales Alfredo Monzón y Nora Laborde. Específicamente, su narrativa aborda a la mujer como sujeto político dentro del ámbito del trabajo y especifica su temática en la labor de mujeres en el frigorífico Swift entre los años 1930 hasta fines de los años 1950 del barrio el Saladillo6.

Además, la exposición recoge las transformaciones de la vida cotidiana que suscitó la incorporación de mujeres en este tipo de trabajos hostiles y las necesidades específicas

${ }^{5}$ Laura Pasquali es historiadora, investigadora y docente; estuvo al frente del proyecto Género, memoria e identidad. Historia de las trabajadoras de la carne del Swift Rosario (1930-1944), una investigación que se convirtió en libro en 2018 y que avanza en el estudio de la problemática incorporando el período 1940 y 1959 (Langone, 17 de abril de 2019).

6 El Saladillo es un emblemático barrio de la zona sur de Rosario, ubicado sobre el margen del arroyo Saladillo y del río Paraná, y a metros de la ciudad vecina de Villa Gobernador Gálvez. Su origen está íntimamente ligado a la instalación de varios frigoríficos que procesaban la carne vacuna criada en la Pampa húmeda para su exportación. El mayor de los frigoríficos era de origen inglés y se denominaba Swift. A su alrededor, se construyeron hermosas casas con un marcado estilo inglés que se conserva hasta la actualidad, dando una singular belleza a la zona. 
Miradas contemporáneas y abordajes museográficos desde lo local en

Artículo la exposición Obreras. Trabajo en el frigorífico y barrio Saladillo

que se disparan en función de los roles sociales tradicionalmente otorgados al sujeto-mujer: desde la reconfiguración de los roles de cuidado hasta la incorporación y acción de mujeres en la vida sindical y en las huelgas, pasando por las problemáticas referidas al género y a la emergencia de un nuevo actor laboral, la inestabilidad de los contratos y la cuestión salarial, el acoso, la enfermedad, entre otros. En palabras del equipo curatorial, Obreras "pretende dar a conocer la historia de las mujeres [que] fueron protagonistas del mundo obrero de una época marcada por grandes transformaciones sociales y políticas" (El Ciudadano, 2019, párr. 3).

\section{Visualidad y experiencia en Obreras. Trabajo en el frigorífico y barrio Saladillo (2019)}

Nos interesa abordar esta exposición tanto por sus nudos problemáticos y por el modo en que se proyectaron en el espacio sus proposiciones visuales y museográficas en el tratamiento de la temática. Destacamos los esfuerzos de montaje y diseño del espacio que invitan a los visitantes a introducirse en una experiencia de inmersión sensorial y afectiva significativa, lo cual permitie otras aproximaciones y lecturas en el espacio expositivo. El abordaje Obreras tiene un matiz histórico, pero encontramos que la construcción expositiva se vincula con un esquema que organiza los elementos y el espacio de forma constelar -en sintonía con las propuestas de experimentación en el espacio- y habilita distintos regímenes espectatoriales. Si bien esta es una muestra proyectada desde la disciplina histórica, encontramos algunos gestos comunes a las exhibiciones del arte contemporáneo y, consecuentemente, a la mixtura disciplinar que proponen los giros temáticos. Al mismo tiempo, estos modos de exhibir no escapan a la influencia de los rasgos de los museos, sus tipologías y sus dinámicas pasadas y actuales. A partir de estas convergencias teórico-metodológicas, consideramos necesario reparar en lo que reconocemos como los distintos núcleos de la exposición, para indagar en el tránsito y la interacción con el espacio y los elementos del montaje.

Al ingresar a la exhibición, el primer espacio funciona como una introducción a la muestra. Esto se logra con la incorporación de un texto en sala con un punteo temático acompañado de una pintura de Aldo Magnani, un artista local que retrata -en un lenguaje moderno- la figura de una obrera, junto a su paleta de pintor y su libreta de la Escuela de Artes Plásticas Musto7. Allí también se encuentra la recepción del museo, con los catálogos

7 La Escuela de Artes Plásticas Manuel Musto es un institución educativa y cultural ubicada en el barrio Saladillo de Rosario. Para conocer más sobre esta institución puede consultarse el sitio web de la Municipalidad de Rosario (s/f).

ESCENA. Revista de las artes, 2021, Vol. 81, Núm. 1 (julio-diciembre), pp. 63-84 
de mano y el personal del Museo que permiten un primer acercamiento. El segundo núcleo, ubicado en la sala contigua, focaliza su atención en la geografía local que aloja el frigorífico Swift con fotos de época exhibidas en marcos montados en la pared y en formato álbum, cada una de ellas acompañada de sus respectivas etiquetas; además, un video que muestra la actualidad de río Saladillo y un mural de la ilustradora Mabel Norma Rodríguez que muestra un mapa ilustrado del barrio. Por último, se ha destinado un sector del núcleo a la interacción del público a partir de la invitación a consignar ¿Cuál es su lugar en el Saladillo?

Luego de atravesar el pasillo -que cuenta con material documental e informativose ubica la sala del frigorífico. Esta última se ha construido a partir de una ambientación escenográfica que utiliza objetos de época con sus etiquetas, vídeos con testimonios, una ambientación que incluye las paredes negras, sonido del ambiente laboral -las sirenas del frigorífico, sonido de animales y herramientas, voces y testimonios de trabajadoras-, una temperatura que se corresponde con el frío del frigorífico, reproducciones de distintos artefactos de la cultura visual y editorial -revistas, panfletos, diarios, afiches y el packaging de productos comestibles de la marca Swift- acompañados por textos en sala, y objetos ligados a la industria cárnica.

El núcleo final se divide en dos espacios: el primero escenifica el interior de una vivienda de barrio, reconstruida con estrategias escenográficas y que incorpora testimonios de obreras inscriptos en pequeños textos sobre las paredes. Al salir por la puerta de la casa, la segunda parte ofrece un recorrido histórico -trabajado con archivos- que tematiza la participación de las mujeres en la vida política más allá de la coyuntura específica del Swift e incorpora siluetas con consignas, apelando a la iconografía del cuerpo femenino en el espacio público. En los lugares de pasaje, además, se ofrecen elementos como poesías o fotografías que apoyan y sostienen la temática.

Nos interesa destacar la cuestión experiencial en esta muestra, ya que Obreras dispone y articula un espacio atravesado por atractores que introducen a los públicos en la experiencia vital del colectivo de las trabajadoras del frigorífico Swift desde diversas estrategias museográficas y visuales. A pesar de que cada espacio refiere a un aspecto específico de la problemática, es interesante pensar el tránsito de uno a otro como pasaje e intersticio: del barrio al frigorífico o a la casa, del trabajo a la privacidad de la vida cotidiana, de la casa a la calle, y viceversa. Otro señalamiento que merece mención es la utilización de la puerta como recurso que concretiza esta idea de pasaje. 
Miradas contemporáneas y abordajes museográficos desde lo local en

Artículo la exposición Obreras. Trabajo en el frigorífico y barrio Saladillo

Imagen 1. Vista general de la Sala del frigoríico

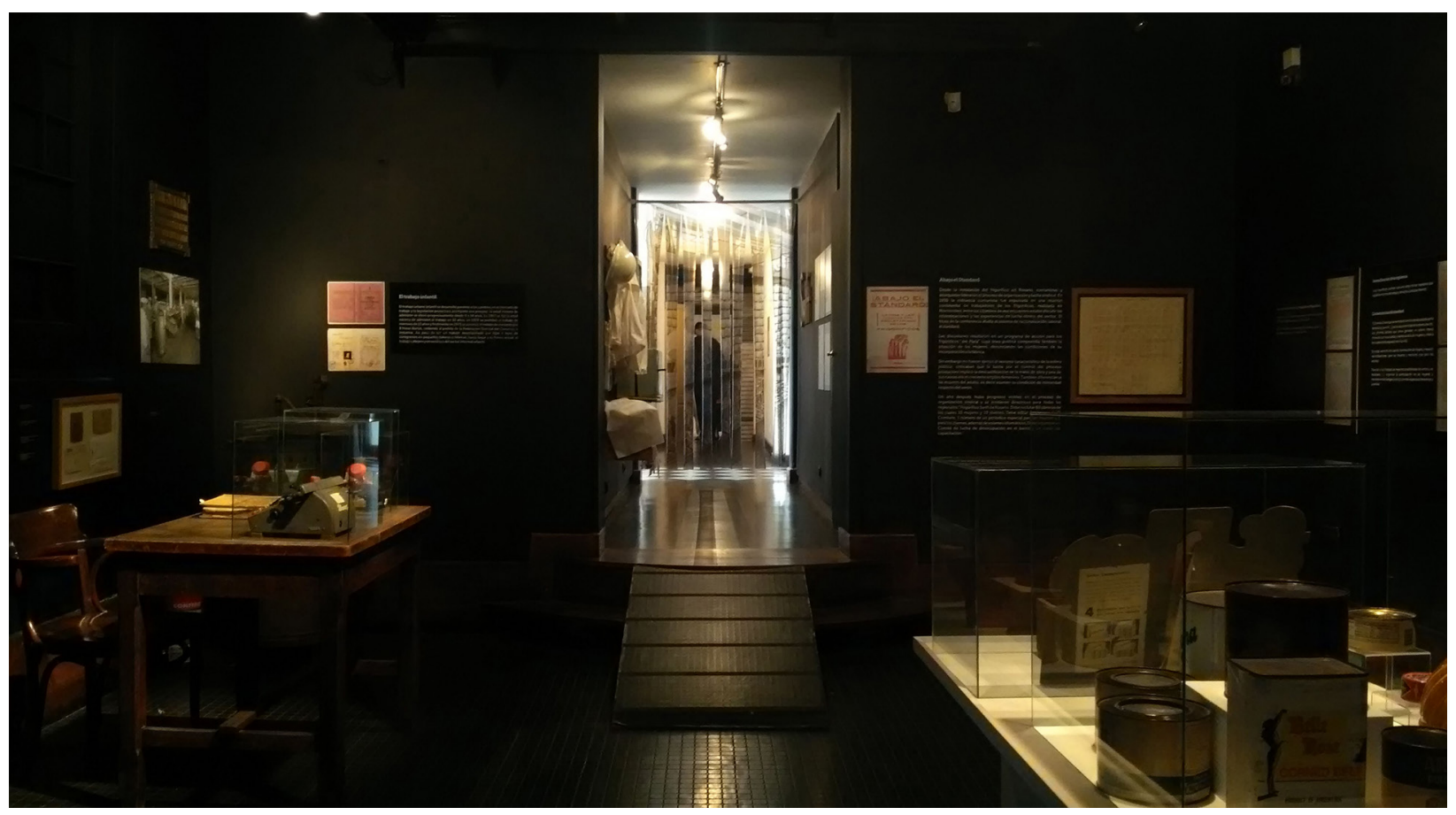

Fuente: Registro fotográfico de la exposición Obreras: Trabajos en el frigorífico y barrio Saladillo (Museo de la Ciudad de Rosario Wladimir Mikielevich), fotografía de María Cecilia Olivari, 2019.

En función de esto, y de los límites de este trabajo, puntualizaremos nuestro análisis en algunos tramos de la exposición que hacen vivida la experiencia de inmersión sensorial y afectiva de los visitantes a la que referimos en apartados anteriores. Abordaremos el tránsito de la vivienda obrera hacia la calle, el acceso al mundo del trabajo, hacia el ingreso a la sala Swift y, por último, marcaremos los recursos museográficos que apelan a la interacción.

Desde el pasillo, el visitante se sumerge en el Rancho, una vivienda obrera que se instala en el cuarto núcleo como un interior dentro del espacio expositivo. La materialidad emula una casa de la clase trabajadora de un barrio periférico, construida con paredes y techo de chapa, ambientado con una mesa pequeña con utensilios para el ritual de tomar mate y dos sillas bajo una ventana que se opone a otra en la pared de frente, además, sobre los muros se emplazan un farol a kerosene, elementos de uso cotidiano, una publicidad de Amargo Obrero ${ }^{8}$

8 El Amargo Obrero es un aperitivo que nació en 1887 en Rosario (Santa Fe, Argentina) como una reacción contra las bebidas dulces que tomaban las clases burguesas. La etiqueta refleja la fuerza del 
y la imagen icónica de Eva Perón. La disposición de la mesa y la ventana emula el espacio representado en la obra de Ernesto de la Cárcova Sin pan y sin trabajo del año $1894^{9}$.

Imagen 2. Sala de la calle durante una de las visitas guiadas del equipo curatorial

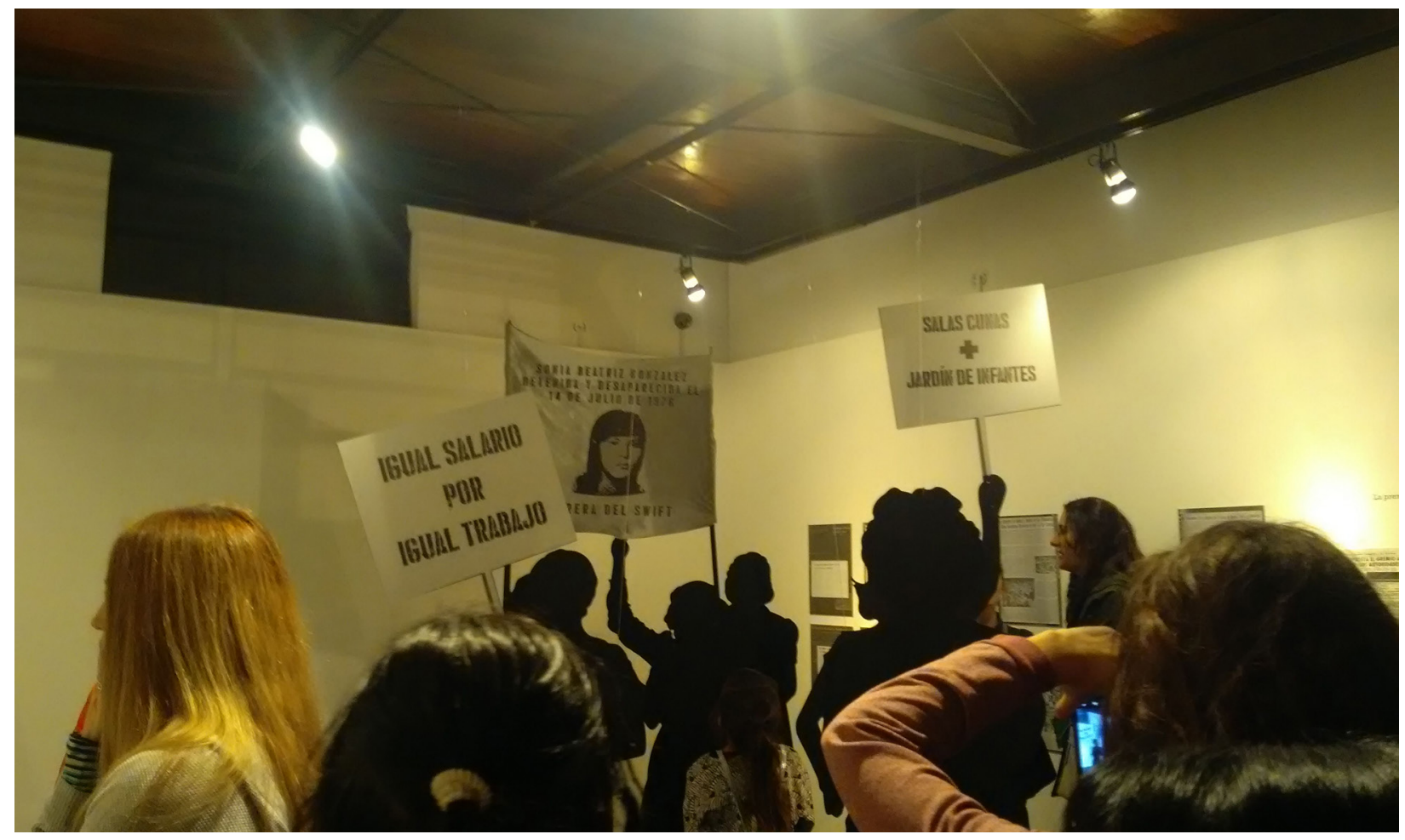

Fuente: Registro fotográfico de la exposición Obreras: Trabajos en el frigorífico y barrio Saladillo (Museo de la Ciudad de Rosario Wladimir Mikielevich), fotografía de María Cecilia Olivari, 2019.

De esta manera, quien visita la vivienda experimenta el espacio en el que moraban los trabajadores que de la Cárcova representa, pero ahora el paisaje que se recorta en la ventana muestra fotografías históricas del barrio Saladillo: en una ventana vemos una casona burguesa y en la opuesta vemos el paisaje con el frigorífico dentro del barrio. Con el

trabajo y las raíces del movimiento obrero, con los colores rojo y negro como símbolo del anarquismo sindicalista. La icónica etiqueta incorpora el slogan "el aperitivo del pueblo argentino" y también recetas para prepararlo que llevan nombres de figuras icónicas de la izquierda argentina como el Che Guevara.

9 Esta obra forma parte de la colección del Museo Nacional de Bellas Artes (Buenos Aires, Argentina). 
Miradas contemporáneas y abordajes museográficos desde lo local en

Artículo la exposición Obreras. Trabajo en el frigorífico y barrio Saladillo

recurso visual de enfrentar las vistas en las ventanas, se visibilizan y tensionan los distintos paisajes demarcados en función de la historia del barrio y de las formas de ocupar y habitar el espacio según la clase social.

Imagen 3. Detalle de la ventana del rancho

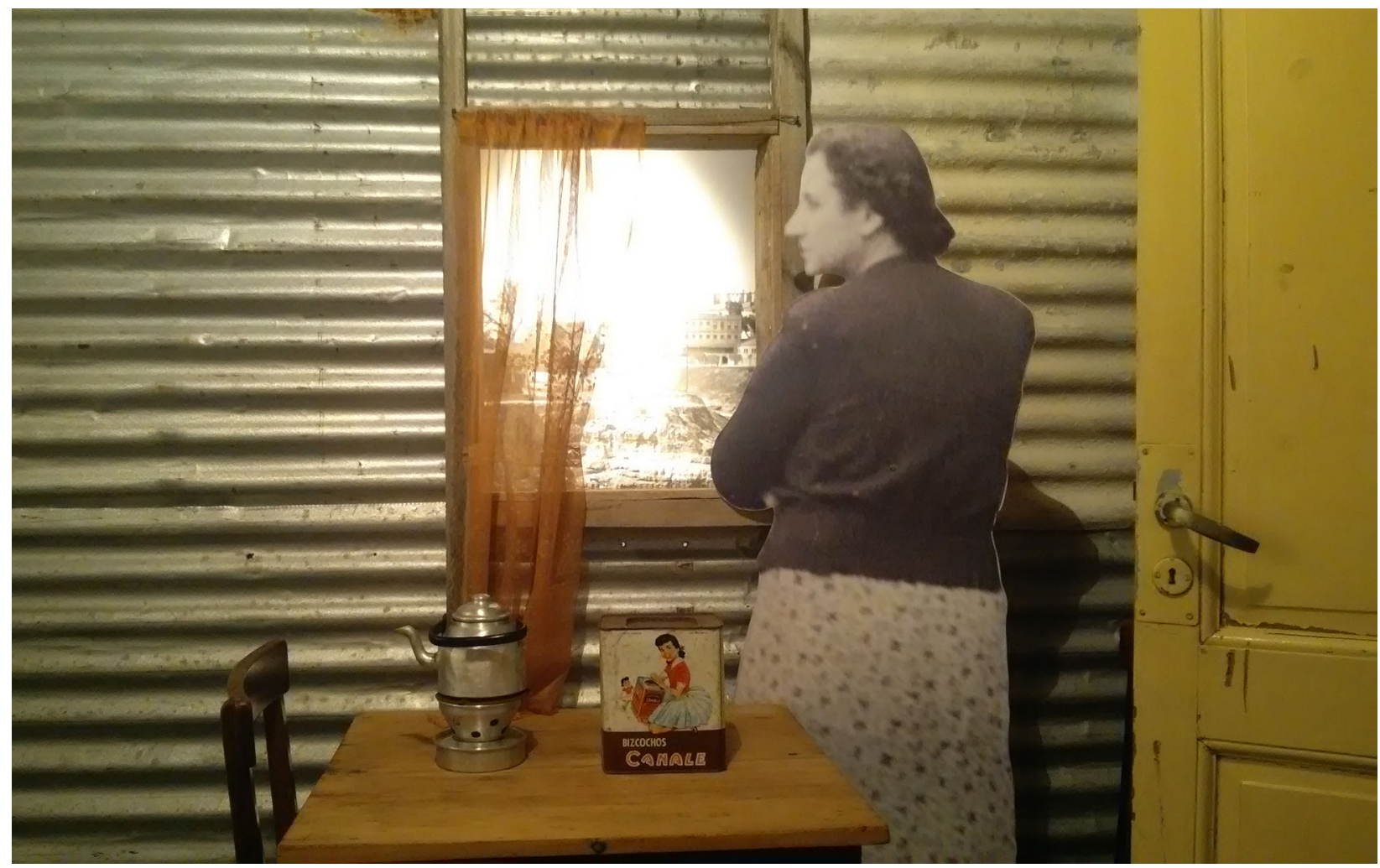

Fuente: Registro fotográfico de la exposición Obreras: Trabajos en el frigorífico y barrio Saladillo (Museo de la Ciudad de Rosario Wladimir Mikielevich), fotografía de María Cecilia Olivari, 2019.

En la pared restante se ubica la puerta de entrada de la casa que desemboca en el segundo espacio -ya mencionado- que identificamos con la calle. Allí, el material de archivo montado en las paredes -fotografías de la época con señalamientos, recortes de diarios y revistas sobre la militancia de mujeres- convive con siluetas femeninas en manifestaciones que levantan consignas icónicas de la militancia sindical y política en Argentina emplazadas en el centro de la sala. Estas siluetas, casi en escala humana, pueden remitir, también, a la 
propuesta iniciada tras la vuelta a la democracia en el proyecto de El Siluetazo ${ }^{10}$, donde la acción performática de hacer presentes las siluetas de los desaparecidos de la dictadura constituye un recurso icónico en el repertorio de estrategias visuales de los grupos sindicales y de Derechos Humanos en Argentina en el reclamo por Memoria, Verdad y Justicia.

La otra puerta que nos interesa destacar es la que nos permite ingresar al mundo del trabajo en el frigorífico. El recurso utilizado es la clásica cortina plástica que se utiliza en lugares vinculados con la manipulación de la carne. Esta, a su vez, está intervenida con fotografías de archivo impresas con heliografía ${ }^{11}$ sobre el material plástico. En el interior de este núcleo, el visitante puede atravesar el ritual del ingreso al Swift vistiendo los delantales blancos característicos, marcando las fichas de entrada y salida, es decir, poniendo en acción los objetos de la escenografía con su propio cuerpo. La luz tenue y focalizada sobre algunos elementos se combina con paredes negras. Los sonidos del ambiente del frigorífico se superponen a las grabaciones de testimonios orales sobre las experiencias laborales y, al mismo tiempo que se tematiza sobre la salud en el trabajo, el tránsito por la sala incorpora la temperatura fría. Así, todos esos recursos permiten experimentar este núcleo como un suceso expositivo dentro del Museo, interpelando senso-afectivamente al visitante.

Otro tipo de inmersión a la sala apela a puestas más tradicionales con objetos, información escrita en las paredes de la sala y reproducciones de materiales visuales. Las condiciones extremas de trabajo emuladas en este ambiente, a su vez, se contraponen con

${ }^{10}$ El Siluetazo tuvo lugar el 21 de septiembre de 1983 y fue una acción colectiva en el espacio público. La performance está vinculada con los conflictos políticos y las desapariciones de persona en el contexto de dictadura en Argentina. Consistía en la creación de siluetas humanas, de tamaño natural, en afiches que luego serían pegados sobre las paredes de la ciudad; además, suponían la participación de la comunidad en general que prestaba su cuerpo para copiar las siluetas. Para profundizar sobre las distintas intervenciones con siluetas puede consultarse Longoni y Bruzzone (2008) y también la entrada sobre Derechos Humanos del proyecto Archivos en uso (s/f), impulsado por la Red Conceptualismos del Sur y el Grupo de Estudios sobre Arte, cultura y política en la Argentina reciente.

${ }^{11}$ El estampado heliográfico es un recurso de producción artístico que, en el ámbito de la ciudad de Rosario, fue utilizado por la artista Graciela Sacco. El caso más emblemático es la Serie Cuerpo a cuerpo desarrollada entre los años 1996 y 2011. Diversas obras integrantes de esta serie forman parte de colecciones en museos público argentinos, entre ellos el Museo Catagnino+Macro de la ciudad de Rosario (Santa Fe, Argentina) y el Museo Nacional de Bellas Artes ubicado en la Ciudad Autónoma de Buenos Aires (Buenos Aires, Argentina). Véase Sacco (2019). 
Miradas contemporáneas y abordajes museográficos desde lo local en

Artículo la exposición Obreras. Trabajo en el frigorífico y barrio Saladillo

las visualidades que se construyen en la retórica de la empresa. Nos anoticiamos de ellos a partir de dispositivos como la revista Swiflandia y las propias fotografías que este medio editorial puso en circulación. Otro elemento visual que se destaca es el contraste del collage fotográfico que contrapone a las trabajadoras, con sus delantales blancos y una imagen pulcra y cuidada, con la imagen de sus compañeros varones con los uniformes manchados por las condiciones del trabajo con la carne.

Imagen 4. Detalle de la entrada de la Sala del frigorífico

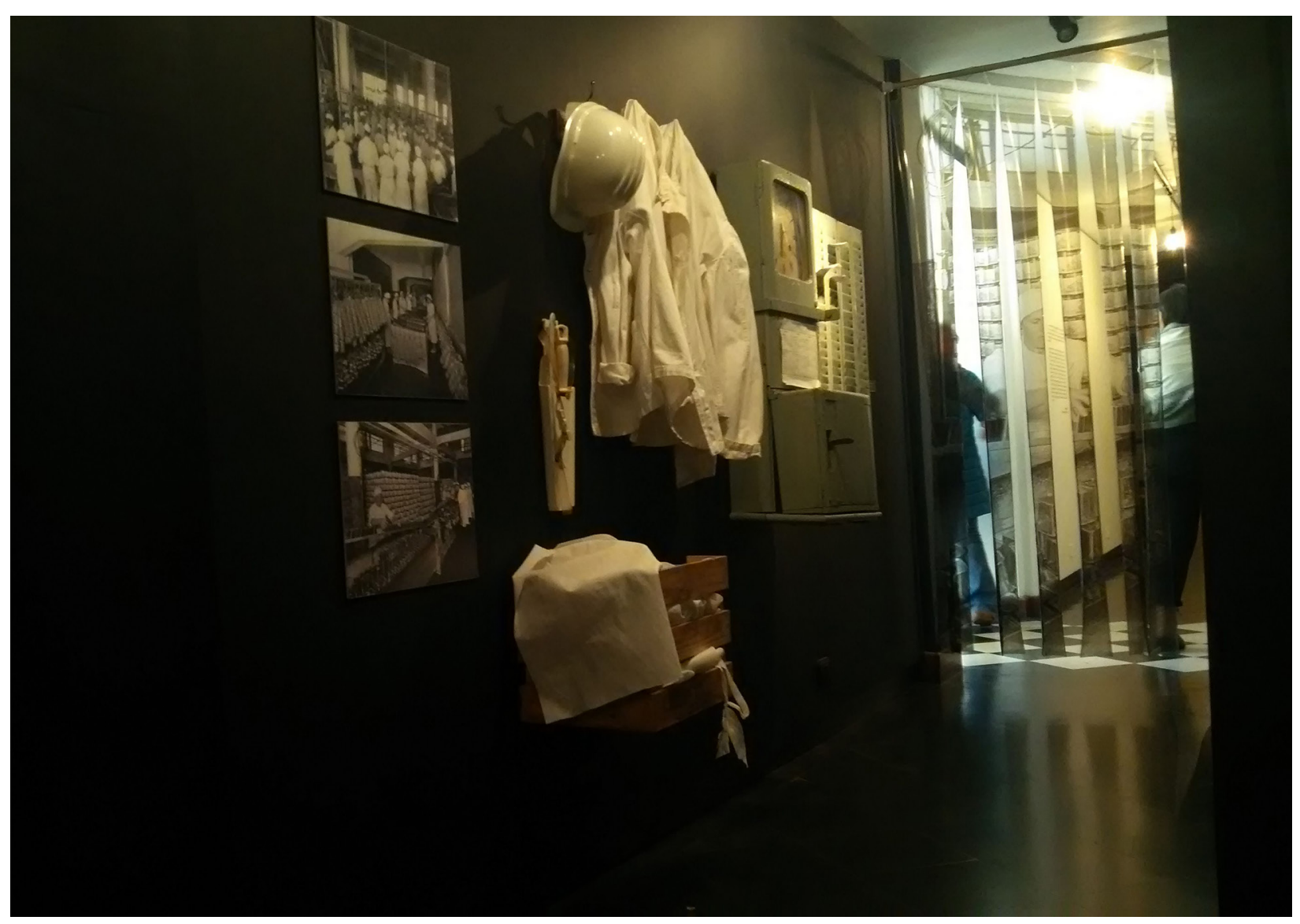

Fuente: Registro fotográfico de la exposición Obreras: Trabajos en el frigorífico y barrio Saladillo (Museo de la Ciudad de Rosario Wladimir Mikielevich), fotografía de María Cecilia Olivari, 2019.

Por último, y en sintonía con esta experiencia cinestésica de Obreras, volvemos a focalizar en el espacio dedicado al registro geográfico anclado en el barrio Saladillo. Si bien esta sala apela a recursos menos escenográficos, destacamos el tratamiento de las 
temporalidades, es decir, la convivencia de distintos lenguajes visuales y audiovisuales centrados en aspectos afectivos de lo espacial. Las fotografías de época muestran formas de habitar el río Saladillo signados por el ocio y el entretenimiento de la clase burguesa y un video en pantalla que muestra una panorámica de la caída del río en la actualidad.

En sistema con la totalidad de la exposición, esta yuxtaposición nos permite evidenciar las transformaciones concretas que ha sufrido el paisaje en el tiempo sobre todo con la irrupción del frigorífico. Otro modo de interpelación del espacio representado se manifiesta en el mapa ilustrado del barrio desde una geografía afectiva y contemporánea que plantea guiños con la invitación a los visitantes a consignar mediante posticks sus experiencias personales vinculadas al Saladillo. Al mismo tiempo, se refuerza una idea que transversaliza toda la exposición y que remite a la construcción del espacio desde la experiencia y el tránsito subjetivo de los paisajes cotidianos.

\section{Precisiones finales}

Por lo desarrollado en este trabajo, reconocemos la pertinencia de exponer Obreras en el contexto del Museo de la Ciudad de Rosario teniendo en cuenta su actual misión y visión institucional. Además, destacamos la confluencia de diversos formatos de experimentación de la exposición que habilitan la desarticulación de las tipologías estancas de los distintos perfiles de museo apelando a estrategias escenográficas y de instalación -en el sentido de instalación que adquiere en el contexto del arte contemporáneo- específicas.

Aunque este museo tiene un perfil que suele vincularse con muestras históricas en un sentido tradicional, el hecho de apelar a recursos museográficos y visuales más próximos a la exposición de arte contemporáneo invita a los públicos a intervenir de diversas maneras. En este sentido, lo que hemos demarcado sobre los modos de exhibir y experimentar permite, en este caso, una pluralidad de regímenes espectatoriales en función de la diversidad de los visitantes, proponiendo tránsitos múltiples y recorridos significativos que conviven sin excluirse ni jerarquizarse. El formato constelar y el recurso temático/metodológico de los giros se conjugan con la experiencia en el espacio, de esta manera los núcleos de la exposición proponen agrupaciones significativas que priorizan la vivencia del visitante.

La museografía ya no se centra en la experimentación que suscita un objeto en particular, sino que se desplaza a la vivencia de un cuerpo recorriendo e interactuando con el espacio y dejándose afectar por los distintos atractores. Así, quién visitó esta muestra tuvo 
Miradas contemporáneas y abordajes museográficos desde lo local en

Artículo la exposición Obreras. Trabajo en el frigorífico y barrio Saladillo

la posibilidad de experimentar interacciones manuales, activando los objetos -vestimenta de trabajo y las tarjetas de entrada y salida del frigorífico- y encarnando distintos roles como la obrera, la ama de casa y la sindicalista. Por otra parte, las experiencias en el aspecto mental permiten experimentar la trasformación del río Saladillo tras la instalación del Swift, mediante un acercamiento al contexto a través de registros fotográficos, diarios, panfletos y revistas de época.

Imagen 5. Detalle de la puerta de entrada a la Sala del frigorífico

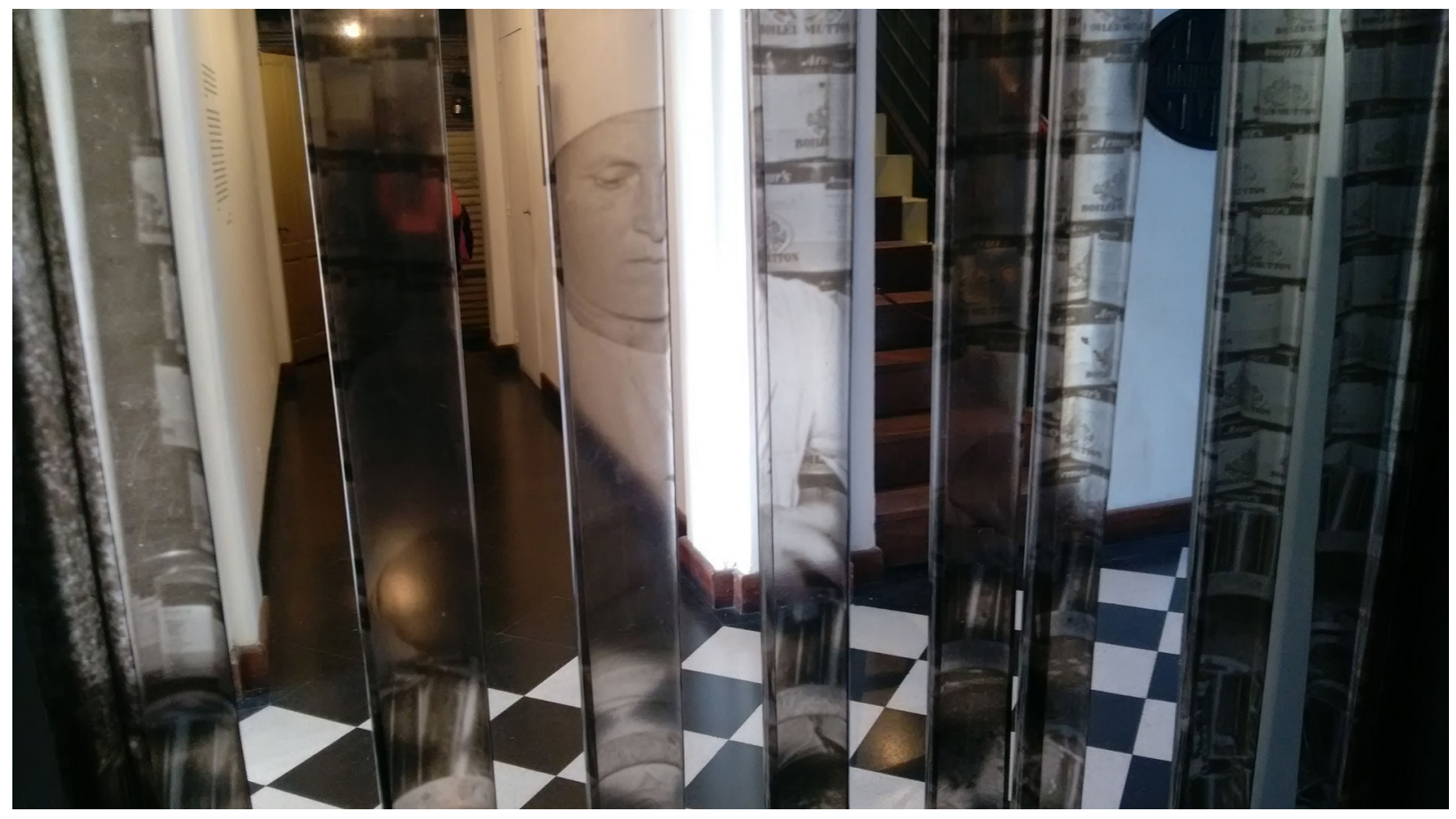

Fuente: Registro fotográfico de la exposición Obreras: Trabajos en el frigorífico y barrio Saladillo (Museo de la Ciudad de Rosario Wladimir Mikielevich), fotografía de María Cecilia Olivari, 2019.

Por último, la experiencia afectiva abarca desde la conexión personal con el lugar, con la identidad de género y de clase, también con los roles laborales y políticos, con lo que interviene de manera transversal todo el espacio expositivo en función de las experiencias particulares de cada visitante y convirtiéndose en el elemento que aglutina y da sentido a la experiencia en esta exposición. En esta línea, Obreras es ejemplar, ya que propone una articulación eficaz de recursos como la temperatura, el sonido y las sonoridades, los 
recursos de iluminación y el color de las paredes, la distribución de los objetos y muebles en el espacio en función de los usos cotidianos y, finalmente, los distintos recursos visuales, audiovisuales y gráficos más próximos a un montaje museográfico tradicional. Por ello, destacamos los aportes del tratamiento de la temática en esta exposición para la inmersión sensorial y afectiva de los visitantes.

Por las consideraciones propuestas en este recorrido, detectamos que Obreras presenta características que ponen en juego aspectos vinculados a lo escenográfico en una clave interactiva, sensorial, afectiva y vivencial, habilitando tránsitos cinestésicos que superponen y concatenan distintos registros de la experiencia del suceso expositivo. El hecho de abordar las exposiciones como sucesos permite incorporar perspectivas transdisciplinares que acojan ideas, epistemes y metodologías diversas en función del proceso de interacción social. Así, las temáticas se nutren de la intersección de distintas áreas del conocimiento ligadas a la historia cultural, la performance cultural y social, las perspectivas de género, la museografía, los estudios sobre la imagen y la cultura visual. 
Miradas contemporáneas y abordajes museográficos desde lo local en

Artículo

la exposición Obreras. Trabajo en el frigorífico y barrio Saladillo

\section{Referencias}

Archivos en uso. (s/f). DDHH. Recuperado de http://www.archivosenuso.org/ddhh/archivo

Bal, M. (2004). El esencialismo visual y el objeto de los Estudios Visuales. Revista Estudios Visuales, (2), 11-49.

Balser, D. (2018). Curacionismo. Cómo la curaduría se apoderó del mundo del arte (y de todo lo demás). Buenos Aires: La Marca Editora.

Bayón F. \& Cuenca Amigo J. (2019). El público una consideración epistemológica. Reflexiones desde la teoría y la práctica. Bilbao: Universidad de Deusto.

Benjamin, W. (2005). Libro de los pasajes. Madrid: Ediciones Akal.

Brea, J. L. (2015). Los Estudios Visuales. La epistemología de la visualidad en la era de la globalización. Madrid: Akal.

Calvi, C. \& D'Amelio, R. (2006). El Museo revelado. Rosario: Editorial Municipal.

Cárcova, E. (1894). Sin pan y sin trabajo [pintura]. Buenos Aires: Museo Nacional de Bellas Artes. Recuperado de https://www.bellasartes.gob.ar/coleccion/obra/1777/

Dewey, J. (2008). El arte como experiencia. Barcelona: Paidós.

El Ciudadano. (17 de abril 2019). Museo de la Ciudad inaugura "Obreras", su nueva muestra. El Ciudadano. Recuperado de https://www.elciudadanoweb.com/inaugura-una-muestra-sobre-obreras-de-frigorificos-en-el-museo-de-la-ciudad/

EVE (2019). Transformando Exposiciones en Experiencias [sitio web]. Recuperado de https:// evemuseografia.com/2019/05/08/transformando-exposiciones-en-experiencias/

Falk, J. \& Dierking, L. (2013). The Museum Experience Revisited. California: Left Coast Press.

Fessel, M. \& Rimini, C. (2019). Fugas y resistencias. Trabajadoras: imagen y representación o hacer visible lo invisible [colección audiovisual]. Rosario: Museo de la Ciudad de Rosario Wladimir Mikielevich.

García Blanco, A. (1999). La exposición. Un medio de comunicación. Madrid: Akal.

Giunta, A. (2016). Verboamerica (catálogo de exposición). Buenos Aires: MALBA Ediciones. 
Guasch, A. M. (2000). El arte último del siglo XX: del posminimalismo a lo multicultural. Madrid: Alianza.

Guasch, A. M. (2003). Un estado de la cuestión. Revista Estudios Visuales, (1), 8-16.

Guasch, A. M. (2016). El arte en la era global.1989-2015. Madrid: Alianza Forma.

Huyssen, A. (2001). En busca del futuro perdido. Cultura y memoria en tiempo de globalización. Buenos Aires: Fondo de Cultura Económica.

Inaugura una muestra sobre obreras de frigoríficos en el Museo de la Ciudad. (11 de abril de 2019). Rosarioshow. Recuperado de https://rosarioshow.com/inaugura-obreras-en-el-museo-de-la-ciudad/

Jiménez Blanco, M. D. (2014). Una historia del museo en nueve conceptos. Madrid: Básicos Arte Cátedra.

Langone, E. (17 de abril de 2019). Género y empleo a través de las historias de las trabajadoras del Swift. Diario La Capital. Recuperado de https://www.lacapital.com.ar/la-ciudad/genero-y-empleo-traves-las-historias-las-trabajadoras-del-swift-n1756063.html

Longoni, A. \& Bruzzone, G. A. (2008). El siluetazo. Buenos Aires: Adriana Hidalgo Editora.

Lucero, M. E. (Comp.) (2016). Políticas de las imágenes en la cultura visual latinoamericana. Mediaciones, dinámicas e impactos estéticos. Rosario: Universidad Nacional del Rosario Editora.

Mitchell, W. J. T. (2009). Teoría de la imagen. Ensayos sobre la representación verbal y visual. Madrid: Akal.

Municipalidad de Rosario. (s.f.). Escuela Municipal de Artes Plásticas Manuel Musto [sitio web]. Recuperado de https://www.rosario.gob.ar/web/ciudad/educacion/escuelas-municipales/escuela-municipal-de-artes-plasticas-manuel-musto

O'Doherty, B. (1999). Inside the White cube. The ideology of the gallery space. Los Angeles: University of California Press.

Panozzo, A. \& Olivari M. C. (2020). La exhibición de arte en la contemporaneidad. Lecturas críticas entre los giros temáticos y el esquema constelar. Revista Arte, Individuo y Sociedad, 32(4), 903-916. doi: https://doi.org/10.5209/aris.64265 
Miradas contemporáneas y abordajes museográficos desde lo local en

Pascuali, L. (Curadora). (2019). Obreras. Trabajos en el frigorífico y barrio Saladillo [muestra museográfica]. Rosario: Museo de la Ciudad de Rosario Wladimir Mikielevich.

Piñero, G. (2013). Re-estructurar el proyecto de un arte latinoamericano: el modelo constelar. Intervención, 4(7), 11-20. doi: https://doi.org/10.30763/Intervencion.2013.7.83

Sacco, G. (2019). Cuerpo a cuerpo [sitio web]. Recuperado de https://gracielasacco.com/ series_de_trabajos/cuerpo-a-cuerpo/

Verón, E (2013) La semiosis social, 2. Ideas, momentos e interpretantes. Buenos Aires: Paidós.

Wagensberg, J. (2001). A favor del conocimiento científico (los nuevos museos). Revista Universitaria de Filosofía Endoxa, (14), 341-356. doi: https://doi.org/10.5944/endoxa.14.2001.5031 